Research Article

\title{
A Study on the Incidence of Surgical site Infections and related Pathogens in Obstetrics \& Gynaecology in a Tertiary Care Hospital in Andaman \& Nicobar Islands
}

\author{
Abhishek Malakar', Parthasarathy Gopalan², Shreya Barik³ ${ }^{3}$, Abhishek Ray ${ }^{4}$ \\ ${ }^{1,3}$ Assistant Professor, ${ }^{4}$ Senior Resident, Department of Obstetrics and Gynaecology, ANIIMS, Port Blair, India. \\ ${ }^{2}$ Associate Professor, Department of Microbiology, ANIIMS, Port Blair, India. \\ DOI: https://doi.org/10.24321/2455.7048.201920
}

I $\quad \begin{array}{lllll}\mathbf{N} & \mathbf{F} & \mathbf{O}\end{array}$

Corresponding Author:

Parthasarathy Gopalan, Department of Microbiology, ANIIMS, Port Blair, India.

E-mail Id:

diraniims@gmail.com

Orcid Id:

https://orcid.org/0000-0001-6163-8495

How to cite this article:

Malakar A, Gopalan P, Barik S, Ray A. A Study on the Incidence of Surgical site Infections and related Pathogens in Obstetrics \& Gynaecology in a Tertiary Care Hospital in Andaman \& Nicobar Islands. Epidem Int 2019; 4(4): 20-24.

Date of Submission: 2019-12-21

Date of Acceptance: 2020-02-04

\section{$\begin{array}{llllllll}\mathbf{A} & \mathbf{B} & \mathbf{S} & \mathbf{T} & \mathbf{R} & \mathbf{A} & \mathbf{C} & \mathbf{T}\end{array}$}

Background: Surgical site infection is one of the most common complications after any operative procedure.

Aim: To determine the incidence of postoperative surgical site infection in Obstetrics and Gynaecology and also to identify the common causative organisms and their susceptibility to antimicrobials.

Material \& Methods: We have analysed data from all the postoperative patients suffering from Surgical Site Infection (SSI), from December 2018 to November 2019 in Andaman and Nicobar Islands Institute of Medical Sciences (ANIIMS).

Result: Overall incidence of SSI was 9.17\%. Staphylococcus aureus was the most common organism identified (38\%), with a high incidence of Methicillin Resistant Staphylococcus Aureus (MRSA) (42.86\%), followed by Pseudomonas (23.91\%). Overall gram-negative bacteria were responsible for more than half of the cases. All the staphylococcal isolates including MRSA were susceptible to linezolid and regarding antibiotic susceptibility of gram-negative organisms, imipenem and piperacillin-tazobactam were most effective.

Conclusion: There is emergence of drug-resistant strains of different bacteria such as Pseudomonas and coagulase-negative Staphylococcus. Injudicious use of antibiotics is one of the reasons for this and, hence, there is need for a proper antibiotic protocol that should be formulated based on local trends and susceptibility of microorganisms.

Keywords: Surgical Site Infection, Caesarean Section, Hysterectomy, MRSA, Pseudomonas, Andaman \& Nicobar

\section{Introduction}

Surgical Site Infection (SSI) is defined as a proliferation of pathogenic microorganisms which develops in an incision site either within the skin and subcutaneous fat (superficial) 
and musculofascial layers (deep) or in an organ or cavity, if opened during surgery. ${ }^{1}$ This is a serious complication after any surgical procedure, and is responsible for $20 \%$ to $25 \%$ of all hospital-acquired infections. ${ }^{2}$ There are many known risk factors to any SSI, including local factors such as hematomas, seromas, suture material, poor surgical technique, degree of contamination and also factors like age, nutrition, hygiene and other associated diseases. This increases the patient morbidity and hospital stay and is a burden to health care system.

In the developed countries, there are established antimicrobial policies; but, on the contrary, in our country, although a national policy of antibiotics for common systemic infections is in place, its application varies widely, mostly due to diverse climatic conditions and population in India, that affects the prevalence of organisms. Poor awareness of national antibiotic policy among doctors, especially general physicians working in remote areas in India, leads to widespread empirical use of antibiotics which is often inappropriate. Emergence of antibiotic resistant organisms has therefore occurred over the years, which is a real threat for future. Local microbial aetiology and susceptibility to antimicrobials, differ in different parts of India, and institutional policies will help in curbing inappropriate antibiotic use.

Andaman and Nicobar Islands Institute of Medical Sciences (ANIIMS) is the only referral tertiary care hospital in Andaman and Nicobar islands. We have conducted this study in the Department of Obstetrics and Gynaecology to know about local bacteriological profile and antibiogram of surgical site infections following obstetric and gynaecological procedures.

\section{Materials and Methods}

This was a cross-sectional study conducted over one year, from December 2018 to November 2019 in the Department of Obstetrics and Gynaecology, Andaman and Nicobar Islands Institute of Medical Sciences (ANIIMS), India. Prior to the sample collection, approval from Institutional Ethical Committee was obtained. Sterile cotton swabs were collected aseptically avoiding skin flora contamination from all the patients having clinical Surgical Site Infection (SSI) fulfilling inclusion and exclusion criteria as follows.

Inclusion Criteria: Patients presenting with SSI after gynaecological and obstetric operations such as elective and emergency Lower Segment Caesarean Section (LSCS), hysterectomies and other gynaecological operations.

Exclusion Criteria: Patients undergoing episiotomy.

All the swabs were placed in sterile test tubes and were sent to Department of Microbiology for bacteriological analysis.

Specimens were inoculated into blood agar and MacConkey's agar and incubated at $35-37^{\circ} \mathrm{C}$ and examined after 24 hours for any growth. Those having no growth were again incubated for 24 hours. Growth on culture plates were identified by colonial morphology, Gram stain and battery of standard biochemical tests. ${ }^{3}$ Antimicrobial susceptibility testing was carried out using Kirby-Baeur disk diffusion method on Mueller Hinton agar as per Clinical Laboratory Standards Institute (CLSI) guidelines. ${ }^{4}$ We presented the data in table formats and analysed using MS Excel and frequency distribution tables.

\section{Result}

Over the period of one year, total 990 caesarean sections and 210 gynaecological operations (hysterectomy, laparotomy and others) were performed. Out of 1200 , there were clinical surgical site infections in 110 cases (9.17\%). Table 1, shows the distribution of SSI in different types of operations, which revealed maximum number of SSI (70 out of 110) occurred in cases of emergency caesarean section, but the incidence of SSI was highest after laparotomy (15\%).

Out of these 110 samples processed, 87 (79\%) yielded bacterial growth. Monomicrobial growth was seen in 82 samples and polymicrobial growth was seen in five cases. Total of 92 bacterial isolates were identified. Majority of the bacteria isolated were gram-negative bacteria ( 49 out of 92 , i.e., $53.26 \%$ ). Overall, Staphylococcus aureus was the predominant bacteria (35 out of 92 i.e. $38 \%$ ) followed by Pseudomonas-aeruginosa (23.91\%) (Table 2).

Table I.Distribution of SSI according to different types of operations

\begin{tabular}{|c|c|c|c|c|}
\hline \multicolumn{2}{|c|}{ Type of Surgery } & Total Number of cases & Surgical Site Infection & Percentage (\%) \\
\hline \multirow{3}{*}{$\begin{array}{c}\text { Gynaecological } \\
\text { Operations }\end{array}$} & Abdominal Hysterectomy & 140 & 10 & 7.14 \\
\cline { 2 - 5 } & Vaginal Hysterectomy & 30 & 02 & 6.67 \\
\cline { 2 - 5 } & Laparotomy & 40 & 06 & 15 \\
\hline \multirow{2}{*}{$\begin{array}{c}\text { Obstetrical } \\
\text { Operations }\end{array}$} & Elective Caesarean Section & 340 & 22 & 6.47 \\
\cline { 2 - 5 } & $\begin{array}{c}\text { Emergency Caesarean } \\
\text { Section }\end{array}$ & 650 & 70 & 10.77 \\
\hline & Total & 1200 & 110 & 9.17 \\
\hline
\end{tabular}


Table 2.Various bacterial isolates obtained from different SSI

\begin{tabular}{|c|c|c|c|c|}
\hline \multicolumn{3}{|c|}{ Type of bacteria } & Number $(n=92)$ & Percentage of isolates (\%) \\
\hline \multirow{4}{*}{$\begin{array}{c}\text { Gram Positive } \\
\qquad(n=43)\end{array}$} & \multirow{2}{*}{$\begin{array}{c}\text { Staphylococcus } \\
\text { Aureus }\end{array}$} & MRSA & 15 & 16.30 \\
\hline & & MSSA & 20 & 21.74 \\
\hline & \multicolumn{2}{|c|}{ Coagulase Negative Staphylococcus } & 07 & 7.60 \\
\hline & \multicolumn{2}{|c|}{ Enterococcus species } & 01 & 1.09 \\
\hline \multirow{6}{*}{$\begin{array}{c}\text { Gram Negative } \\
\qquad(n=49)\end{array}$} & \multicolumn{2}{|c|}{ Pseudomonas Aeruginosa } & 22 & 23.91 \\
\hline & \multicolumn{2}{|c|}{ Escherichia coli } & 12 & 13.04 \\
\hline & \multicolumn{2}{|c|}{ Klebsiella species } & 08 & 8.70 \\
\hline & \multicolumn{2}{|c|}{ Acinetobacter species } & 03 & 3.26 \\
\hline & \multicolumn{2}{|c|}{ Citrobacter species } & 02 & 2.18 \\
\hline & \multicolumn{2}{|c|}{ Proteus species } & 02 & 2.18 \\
\hline
\end{tabular}

Table 3.Susceptibility pattern of bacteria isolates

\begin{tabular}{|c|c|c|c|c|c|c|c|c|c|}
\hline Bacteria & Amp & Ak & Gen & Cip & Aug & Ipm & Cfs & Pit & Lz \\
\hline $\begin{array}{l}\text { S.Aureus } \\
\text { MSSA (20) }\end{array}$ & $\begin{array}{c}06 \\
(30 \%)\end{array}$ & $\begin{array}{c}16 \\
(80 \%)\end{array}$ & $\begin{array}{c}08 \\
(40 \%)\end{array}$ & $\begin{array}{c}09 \\
(45 \%)\end{array}$ & $\begin{array}{c}15 \\
(75 \%)\end{array}$ & NT & $\begin{array}{c}15 \\
(75 \%)\end{array}$ & $\begin{array}{c}17 \\
(85 \%)\end{array}$ & $\begin{array}{c}20 \\
(100 \%)\end{array}$ \\
\hline $\begin{array}{c}\text { Coagulase } \\
\text { Negative } \\
\text { Staphylococcus } \\
(07)\end{array}$ & $\begin{array}{c}02 \\
(28.56 \%)\end{array}$ & $\begin{array}{c}04 \\
(57.14 \%)\end{array}$ & $\begin{array}{c}03 \\
(42.86 \%)\end{array}$ & $\begin{array}{c}02 \\
(28.57 \%)\end{array}$ & $\begin{array}{c}05 \\
(71.43 \%)\end{array}$ & NT & NT & NT & $\begin{array}{c}07 \\
(100 \%)\end{array}$ \\
\hline $\begin{array}{c}\text { Enterococcus } \\
(01)\end{array}$ & 00 & $\begin{array}{c}01 \\
(100 \%)\end{array}$ & $\begin{array}{c}01 \\
(100 \%)\end{array}$ & NT & $\begin{array}{c}01 \\
(100 \%)\end{array}$ & NT & NT & NT & $\begin{array}{c}01 \\
(100 \%)\end{array}$ \\
\hline $\begin{array}{l}\text { P.Aeruginosa } \\
\text { (22) }\end{array}$ & $\begin{array}{c}07 \\
(31.81 \%)\end{array}$ & $\begin{array}{c}15 \\
(68.19 \%)\end{array}$ & $\begin{array}{c}12 \\
(54.55 \%)\end{array}$ & $\begin{array}{c}08 \\
(36.36 \%) \\
\end{array}$ & $\begin{array}{c}14 \\
(63.64 \%) \\
\end{array}$ & $\begin{array}{c}17 \\
(77.27 \%)\end{array}$ & $\begin{array}{c}15 \\
(68.18 \%) \\
\end{array}$ & $\begin{array}{c}22 \\
(100 \%)\end{array}$ & NT \\
\hline $\begin{array}{l}\text { E.Coli } \\
(12)\end{array}$ & $\begin{array}{c}04 \\
(33.33 \%)\end{array}$ & $\begin{array}{c}06 \\
(50 \%)\end{array}$ & $\begin{array}{c}03 \\
(25 \%)\end{array}$ & $\begin{array}{c}05 \\
(41.67 \%)\end{array}$ & $\begin{array}{c}09 \\
(75 \%)\end{array}$ & $\begin{array}{c}12 \\
(100 \%)\end{array}$ & $\begin{array}{c}10 \\
(83.33 \%)\end{array}$ & $\begin{array}{c}11 \\
(91.67 \%)\end{array}$ & NT \\
\hline $\begin{array}{l}\text { Klebsiella } \\
\text { (08) }\end{array}$ & $\begin{array}{c}04 \\
(50 \%)\end{array}$ & $\begin{array}{c}05 \\
(62.5 \%)\end{array}$ & $\begin{array}{c}05 \\
(62.5 \%)\end{array}$ & $\begin{array}{c}04 \\
(50 \%)\end{array}$ & $\begin{array}{c}07 \\
(87.50 \%)\end{array}$ & $\begin{array}{c}06 \\
(75 \%)\end{array}$ & $\begin{array}{c}07 \\
(87.50 \%)\end{array}$ & $\begin{array}{c}07 \\
(87.50 \%)\end{array}$ & NT \\
\hline
\end{tabular}

Amp: Ampicillin, Ak: Amikacin, Gen: Gentamycin, Cip: Ciprofloxacin, Aug: Augmentin, Ipm: Imipenam, Cfs: Cefeperazone/Sulbactum, Pit: Piperacillin/Tazobactum, Lz: Linezolid.

All the isolates of MRSA (15) were susceptible to linezolid and vancomycin.

Regarding antibiotic susceptibility (Table 3), all the staphylococcal isolates including MRSA and CONS were susceptible to Linezolid. Pseudomonas was the second commonest organism isolated, which was sensitive to piperacillin-tazobactum and imipenem. Same sensitivity pattern was also observed with EscherichiaColi and Klebsiella too.

\section{Discussion}

This study over 1 year in the only referral tertiary care hospital of Andaman and Nicobar Islands showed that the overall incidence of SSI following gynaecological and obstetrical operations was $9.17 \%$ which was comparable with the study done by Harish Babu et al. and another study by Dessie et al. but much less than the finding of a similar study conducted in Punjab (18.88\%)..$^{5,6,7}$ Incidence of postoperative wound infection was much more in emergency LSCS compared to elective LSCS $(10.77 \%$ vs. $6.47 \%$ ). Overall incidence of SSI following caesarean section varies from $0.3 \%$ to $51.17 \%$ in various studies. ${ }^{8,9,10,11}$ Diabetes, anaemia, advancing age, increased duration of operations were some of the known risk factors.

We found the incidence of SSI following abdominal hysterectomy was $7.14 \%$, which was similar to the study by Harish Babu et al. ${ }^{5}$ In contrast, incidence of SSI following laparotomy was $15 \%$, which was the highest due to the frequent presence of other comorbidities among these patients who were taken for laparotomy due to various indications and also due to large amount of blood loss and frequent placement of drains which also act as a source of infection from external environment. 
The principal microorganisms that cause wound infections after obstetric or gynecologic surgery are aerobic staphylococci and streptococci, which are inoculated into the wound from the skin and aerobic Gram-negative bacilli (such as E. coli, K. pneumoniae and Proteus species) and anaerobes, which are transferred from the pelvic cavity as the surgeon closes the abdominal wound. In our study, we found that Staphylococcus aureus was the most common isolate identified. Similarly different studies from different parts of India concluded that Staphylococcus aureus was the most common causative organism for SSI. ${ }^{5,7,12}$ We have found methicillin resistance in 15 out of 35 isolates of Staphylococcus, that is, $42.86 \%$ of staphylococci are MRSA strain. This finding was evidently more than some contemporary studies, who found MRSA in the range of $10 \%$ to $21 \% .{ }^{12,13,14}$ Eagye et al. had found the incidence of MRSA as $45 \%$, which was close to our finding. ${ }^{15}$ So, there is definitely an increasing trend of MRSA, which can be attributed to rampant use of antibiotics by general physicians to treat common infections caused by Staphylococcus. Regarding antibiotic sensitivity, we did not find any resistance to linezolid or vancomycin in the MRSA group. We also did not find any resistance to linezolid and vancomycin among the coagulase-negative Staphylococcus aureus (CONS) group, which is definitely a positive finding in the present scenario, where there is already case reports of vancomycin-resistant CONS strains. This finding may be helpful in treating MRSA and CONS infections in future.

Gram-negative infections were responsible for more than half of all the SSIs (53.26\%). In this group, Pseudomonas was the commonest (23.91\%), followed by E. coli (13.04\%). This finding was consistent with the findings by Masaadeh HA et al. and Sohn et al., who found it to be the most common isolate. ${ }^{16,17}$ But conversely studies by Negi et al. and Dessie et al. showed that E.Coli was more prevalent than Pseudomonas. ${ }^{6,12}$ We found a higher prevalence of Pseudomonas (23.91\%) compared to other studies by Kaur (15\%) and Mundhada et al. (12\%).,18 Only one study from Southern India came out with a similar incidence of Pseudomonas in SSI, that is, $24.13 \% .^{5}$

P.aeruginosa strains were moderately sensitive to gentamicin, amikacin and cefoperazone sulbactum with susceptibility in the range of $50 \%$ to $70 \%$ and $100 \%$ sensitive to piperacillin-tazobactum. This bacterial isolate of Pseudomonas was more resistant than previous studies and clearly indicates that the Pseudomonas strains are becoming more resistant to the commonly prescribed antibiotics day by day and is a definite concern to the clinicians. ${ }^{16}$ Other common gram-negative isolates were also highly resistant to ampicillin and sensitive to imipenem, amoxycillin-clavulanic acid and piperacillin-tazobactum. This development of highly resistant bacterial strain has been a global problem and our study also points to the same.

\section{Conclusion}

Surgical site infection is a nightmare to every surgeon and meticulous operative technique, maintenance of proper asepsis, decontamination of operation theatres and timely administration of appropriate preoperative antibiotics are necessary to prevent this. But when it cannot be prevented, it must be treated effectively and for that we need to start the appropriate and most effective antibiotic. This study helped us to get an insight into local microbial aetiology in obstetrics and gynaecological surgeries as well as their susceptibility pattern to antibiotics. Furthermore, the high prevalence of antibiotic-resistant strains also point to the concerning problem of irrational and prolonged use of antibiotics, which needs to be taken care of immediately by proper formulation of local institutional antimicrobial policies.

Informed consent was obtained from individual participants included in the study.

Funding: No funding sources

\section{Conflict of Interest: None}

\section{References}

1. Bagnall NM, Vig S, Trivedi P. Surgical-site infection. Surgery 2009; 27(10): 426-430. Available from: https://www.surgeryjournal.co.uk/article/S02639319(09)00174-4/abstract [PubMed/ Google Scholar]

2. Mawalla B, Mshana SE, Chalya PL, Imirzalioglu C, Mahalu W. Predictors of surgical site infections among patients undergoing major surgery at Bugando Medical Centre in Northwestern Tanzania. BMC Surgery 2011; 11: 21. Available from: https://bmcsurg.biomedcentral. com/articles/10.1186/1471-2482-11-21 [PubMed/ Google Scholar/ ResearchGate].

3. Koneman EW, Allen SD, Jande WM, Schreckenberger PC, Winn WC Jr. Koneman's Colour Atlas and Textbookof Diagnostic Microbiology. $6^{\text {th }}$ ed. Philadelphia: Lippincott Williams; 2006.

4. Clinical Laboratory Standards Institute. Performance standards for antimicrobial susceptibility testing, $27^{\text {th }}$ ed, 2017. CLSI supplement M100, Wayne PA, USA.

5. Harish Babu BG, Narmadha NS, Soujanya L, Rathika R, Haja Abdul Nazeer MJ. Surgical Wound Infections in Obstetrics and Gynaecology - A Study from Rural Tertiary Care Hospital. International Journal of Innovative Research in Medical Science. December 2017; 2(12): 1569-1572. Available from: https://ijirms. in/index.php/ijirms/article/view/209 [Google Scholar].

6. Dessie W, Mulugeta G, Fentaw S, Mihret A, Hassen M, Abebe E. Pattern of Bacterial Pathogens and their Susceptibility Isolated from Surgical Site Infections at Selected Referral Hospitals, Addis Ababa, Ethiopia. Int J Microbiol 2016; 2016: 2418902. 
Available from: http://downloads.hindawi.com/ journals/ijmicro/2016/2418902.pdf [DOI: https:// doi.org/10.1155/2016/2418902/ PubMed/ Google Scholar].

7. Kaur K, Oberoi L, Devi P. Bacteriological profile of surgical site infections. IAIM 2017; 4(12): 77-83. Available from: https://iaimjournal.com/wp-content/ uploads/2017/12/iaim_2017_0412_14.pdf [Google Scholar].

8. Bhadauria AR, Hariharan C. Clinical study of postoperative wound infections in obstetrics and gynaecological surgeries in a tertiary care set up. Int J Reprod Contracept Obstet Gynecol 2013; 2: 631-638. Available from: https://www.ijrcog.org/index.php/ ijrcog/article/view/259 [Google Scholar].

9. Yalçin AN, Bakir M, Bakici Z, Dökmetas I, Sabir N. Postoperative wound infections. J Hosp Infect 1995; 29(4): 305-309. Available from: https://www.journalofhospita linfection.com/article/0195-6701(95)90278-3/pdf [PubMed].

10. Starling CE, Couto BR, Pinheiro SMC. Applying the centers for disease control and prevention and national nosocomial surveillance system methods in Brazilian hospitals. Am J Infect Control 1997; 25(4): 303-311. Available from: https://www.ajicjournal.org/article/ S0196-6553(97)90022-5/pdf [PubMed/ Google Scholar].

11. Eltahawy AT, Mokhtar AA, Khalaf RM, Bahnassy AA. Postoperative wound infection at a university hospital in Jeddah, Saudi Arabia. J Hosp Infect 1992; 21: 79-83. [PubMed/ Google Scholar].

12. Negi V, Pal S, Juyal D, Sharma MK, Sharma N. Bacteriological Profile of Surgical Site Infections and Their Antibiogram: A Study From Resource Constrained Rural Setting of Uttarakhand State, India. J Clin Diagn Res 2015; 9(10): DC17-DC20. [PubMed/ Goolge Scholar].

13. Aggarwal A, Khanna S, Arora U, Devi P. Correlation of beta-lactamase production/methicillin resistance and phage pattern of Staphylococcus aureus. Indian J Med Sci 2001; 55(5): 253-256. [PubMed/ Google Scholar].

14. Kownhar H, Shankar EM, Vignesh R, Sekar R, Velu V, Rao UA. High isolation rate of Staphylococcus aureus from surgical site infections in an Indian hospital. J Antimicrob Chemother 2008; 61: 758-760. [PubMed/ Google Scholar].

15. Eagye KJ, Kim A, Laohavaleeson S, Kuti JL, Nicolau DP. Surgical site infections: does inadequate antibiotic therapy affect patient outcomes? SurgInfect (Larchmt) 2009; 10(4): 323-331. [PubMed/ Google Scholar].

16. Masaadeh HA, Jaran AS. Incident of Pseudomonas aeruginosa in post-operative wound infection. Am J Infect Dis 2009; 5: 1-6. Available from: https:// thescipub.com/pdf/10.3844/ajidsp.2009.1.6 [Google
Scholar].

17. Sohn AH, Parvez FM, Vu T, Hai HH, Bich NN, Le Thu TA. Prevalence of surgical-site infections and patterns of antimicrobial use in a large tertiary-care hospital in Ho Chi Minh City, Vietnam. Infect Control Hosp Epidemiol 2002; 23(7): 382-387. [PubMed/ Google Scholar].

18. Mundhada AS, Tenpe S. A study of organisms causing surgical site infections and their antimicrobial susceptibility in atertiary care Government Hospital. Indian J Pathol Microbiol 2015; 58(2): 195-200. Available from: http://www.ijpmonline.org/article. asp issn=0377-4929; year $=2015$; volume $=58$; issue $=2$ ;spage $=195$; epage $=200$; aulast=Mundhada [Google Scholar]. 